\title{
Age-based demography of humpback grouper Cromileptes altivelis: implications for fisheries management and conservation
}

\author{
Ashley J. Williams ${ }^{1,7, *}$, Campbell R. Davies ${ }^{2}$, Bruce D. Mapstone ${ }^{3}$, \\ Leanne M. Currey ${ }^{1}$, David J. Welch ${ }^{1,4}$, Gavin A. Begg ${ }^{5}$, Aaron C. Ballagh ${ }^{1}$, \\ J. Howard Choat ${ }^{6}$, Cameron D. Murchie ${ }^{1}$, Colin A. Simpfendorfer ${ }^{1}$ \\ ${ }^{1}$ Fishing and Fisheries Research Centre, School of Earth and Environmental Science, James Cook University, \\ Queensland 4811, Australia \\ ${ }^{2}$ CSIRO Marine and Atmospheric Research, GPO Box 1538, Hobart,Tasmania 7001, Australia \\ ${ }^{3}$ Centre for Australian Weather \& Climate Research, a partnership between CSIRO and the \\ Australian Bureau of Meteorology, GPO Box 1538, Hobart, Tasmania 7001, Australia \\ ${ }^{4}$ Queensland Primary Industries and Fisheries, Department of Employment, Economic Development and Innovation, \\ PO Box 1085, Oonoonba, Queensland 4811, Australia \\ ${ }^{5}$ Bureau of Rural Sciences, Department of Agriculture, Fisheries and Forestry, GPO Box 858, Canberra, ACT 2601, Australia \\ ${ }^{6}$ School of Marine and Tropical Biology, James Cook University, Queensland 4811, Australia \\ ${ }^{7}$ Present address: Oceanic Fisheries Programme, Secretariat of the Pacific Community, BP D5, 98848 Noumea, New Caledonia
}

\begin{abstract}
The humpback grouper Cromileptes altivelis is listed as Vulnerable on the IUCN Red List because of concerns about unsustainable levels of harvest. Quantitative estimates of life history parameters are scarce, limiting formal assessment of long-term harvest rates and conservation risk and the design of robust management measures. We provide the first estimates of age-based population parameters for $C$. altivelis, using samples from the Great Barrier Reef (GBR) and Torres Strait, Australia. Population parameters did not differ significantly between regions. The maximum observed age was $19 \mathrm{yr}$, the von Bertalanffy growth parameters were $K=0.30 \mathrm{yr}^{-1}, L_{\infty}=597 \mathrm{~mm}$, and total mortality rate, estimated from an age-based catch curve, was $0.26 \mathrm{yr}^{-1}$. Preliminary estimates of natural mortality for the GBR, based on samples from reefs closed to fishing, were $0.23 \mathrm{yr}^{-1}$ (Hoenig regression) and $0.26 \mathrm{yr}^{-1}$ (catch curve), suggesting recent fishing mortality was low. C. altivelis was found to be a protogynous hermaphrodite with $50 \%$ of individuals being male at length $547 \mathrm{~mm}$ and age 9.6 yr. Peak spawning was between October and January. These results contrast with previous perceptions of life history traits of this species and suggest that $C$. altivelis may not be as vulnerable to managed fishing pressure as previously thought. Notwithstanding this, there remains considerable uncertainty in unfished abundance and average recruitment levels for $C$. altivelis populations. We consider a combination of management strategies including size limits, effort controls and no-take areas that are likely to be most effective in minimising the conservation risk for C. altivelis populations and provide sustainable yields across the species' range.
\end{abstract}

KEY WORDS: Humpback grouper - Cromileptes altivelis - Conservation - Fisheries management · Age-based demography · Great Barrier Reef · Torres Strait · Coral reef

Resale or republication not permitted without written consent of the publisher

\section{INTRODUCTION}

The humpback grouper Cromileptes altivelis is an iconic species of coral reef fish distributed throughout tropical East Asia straddling the western margin of the
Pacific and eastern margin of the Indian Oceans (Heemstra \& Randall 1999). Heemstra \& Randall (1999) classified $C$. altivelis as a unique monotypic genus within the family Serranidae, but recent work by Craig \& Hastings (2007) has demonstrated that C. altivelis 
nests within the Epinephelus genus in a clade with other large species including E. lanceolatus, E. fuscoguttatus and E. polyphekadion. C. altivelis is distinctive because of its unusual high dorsal profile, although this feature is also evident in the other serranid genera Alphestes and Dermatolepis. Juvenile C. altivelis are prize targets for the aquarium trade throughout the species' distribution, and adults are among the most valued products in the Asian live reef fish trade (Sadovy et al. 2008). The current, largely unmanaged, harvests of $C$. altivelis in many south-east Asian and south Pacific waters are generally considered to be unsustainable and pose a serious conservation risk to the species and long-term yields (Sadovy et al. 2008). This concern has been supported by studies documenting large targeted catches of this and other reef species and the infrequent observations of the species in Indonesia and Malaysia, where the species was previously considerably more abundant (Oakley et al. 1999, Sadovy et al. 2003, Pet-Soede et al. 2004). C. altivelis was listed as Vulnerable on the IUCN Red List in 2007 (Sadovy et al. 2008) in response to concerns over declines in many populations, the limited understanding of their life history traits, and high exploitation rates in response to demand in the live fish and aquarium trade.

There are no published studies that provide agebased estimates of life-history parameters required to evaluate the likely performance of alternative harvest and conservation strategies for Cromileptes altivelis. The limited information available for wild populations suggests that $C$. altivelis is likely to be naturally low in abundance (Sabetian 2003, Pears 2005), slow-growing and long-lived (Oakley et al. 1999, Morris et al. 2000, Sabetian 2003, Teh et al. 2005) relative to common perceptions of tropical reef fish species. C. altivelis represents a relatively low proportion of catches in commercial reef line fisheries relative to other species (Samoilys et al. 2002, Williams et al. 2008a) despite growing demand and prices as high as \$ US130 $\mathrm{kg}^{-1}$ in select markets (Sadovy et al. 2003). The combination of low abundance and high value has driven research on aquaculture and hatchery rearing of this species (Mous 2000, Sugama et al. 2003) in an attempt to capitalise on the unmet demand for $C$. altivelis in live reef fish markets. Observations from the aquaculture industry suggest that $C$. altivelis is a protogynous hermaphrodite (Liu \& Sadovy de Mitcheson 2009), but this has not been confirmed through histological analysis.

Cromileptes altivelis occurs in tropical waters across northern Australia, including the Great Barrier Reef (GBR), the coral reefs of the Torres Strait (TS) and the tropical fringing reefs of the Northern Territory and Western Australia (Heemstra \& Randall 1999). The species was regularly taken on the GBR by a multi- species reef line fishery, with a reported annual commercial catch ranging from 19.5 to 27.8 t between 2000 and 2003 (Coastal Habitat Resources Information System, Queensland Department of Primary Industries and Fisheries: http://chrisweb.dpi.qld.gov.au/CHRIS/), until it was protected under Queensland state fisheries legislation in 2004. C. altivelis is harvested in the TS by both indigenous and non-indigenous commercial fishers as part of the multi-species reef line fishery (Williams et al. 2008a). A moratorium on the sale of live fish exists in the TS (Mapstone et al. 2003), but $C$. altivelis is still taken and marketed as a whole, gilled and gutted product. C. altivelis comprises a small proportion (1 to $2 \%$ ) of the commercial harvest by numbers in the TS (Williams et al. 2008a) but it is a valuable and sought-after component of the catch. There is no current stock assessment or estimate of sustainable exploitation rates on which to base harvest regulations for either the GBR or TS.

This paper provides the first estimates of age-based population parameters for Cromileptes altivelis. These are necessary to assess status of populations and the impacts of fishing and to evaluate the likely performance of alternative fisheries and conservation management strategies. Parameter estimates are provided for the length-weight relationship, length and age distributions, growth and mortality rates, spawning season, length and age at maturity, and length and age at sex change, obtained from long-term monitoring and research on reef fishes from the GBR (Mapstone et al. 2004) and TS (Williams et al. 2008a). On the basis of these estimates, we make some general observations on current perceptions of the relative vulnerability of C. altivelis to fishing and suggest appropriate management approaches.

\section{MATERIALS AND METHODS}

Sample collection. GBR: In total, 225 Cromileptes altivelis were sampled from 6 reefs at each of 4 latitudes (areas) along the GBR (Lizard Island, Townsville, Mackay and Storm Cay) over 11 yr from 1995 to 2005 during the Effects of Line Fishing (ELF) Experiment catch surveys (Mapstone et al. 2004; Fig. 1). All samples were collected using standardised commercial line fishing gear. Four reefs within each area were closed to fishing for up to $12 \mathrm{yr}$ prior to sampling, while the other 2 reefs had always been open to fishing but there were too few samples collected from open reefs to compare life history parameters between open ( $\mathrm{n}=$ 57 ) and closed ( $n=167$ ) reefs. Accordingly, it was necessary to pool the data across open and closed reefs and all 4 areas for most analyses, meaning that parameter estimates are likely to be influenced to some 


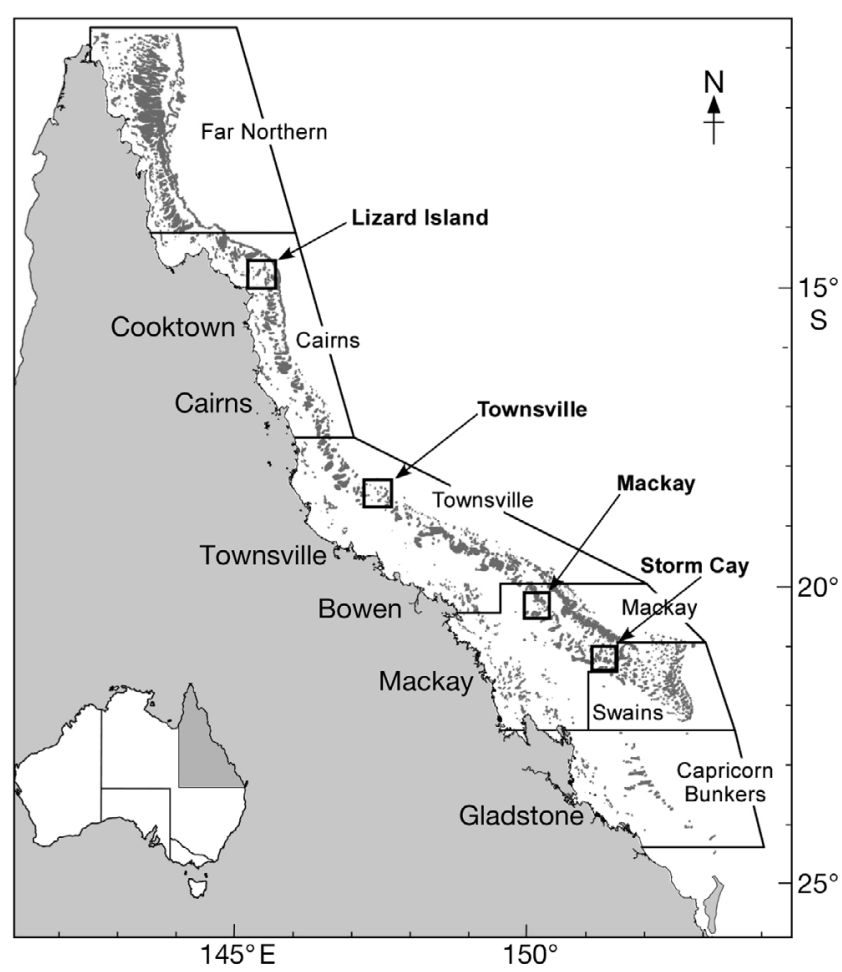

Fig. 1. Location of the 6 reefs within 4 areas of the Great Barrier Reef sampled for the Effects of Line Fishing experiment

degree by exploitation prior to $C$. altivelis becoming a no-take species on the GBR and by any latitudinal variation over the southern half of the GBR.

An additional 22 Cromileptes altivelis samples from the GBR were provided by commercial and recreational fishers and recreational spear fishers. These samples were not used for estimates of age and length frequency distributions or to estimate mortality due to the potential biases associated with different fishing gear selectivities. Fork length $(F L)$ of all samples was measured to the nearest $\mathrm{mm}$, and whole wet weight $(W)$ was measured to the nearest $10 \mathrm{~g}$. Sagittal otoliths were removed, cleaned of any residual material and stored dry. Gonads were removed and stored in $10 \%$ phosphate buffered formalin.

TS: Fifty-seven Cromileptes altivelis were collected from reefs open to fishing in the TS (Fig. 2) during observer surveys on board indigenous and non-indigenous commercial vessels. Five 2 wk observer surveys were completed with the nonindigenous commercial fishers in 2004, while 3 observer surveys were completed with the indigenous commercial fishers in 2005 and 2006 (Williams et al. 2008a). An additional 145 C. altivelis were obtained from reefs open to fishing from March 2004 to November 2005 by monthly purchases from indigenous and non-indigenous commercial operators in the TS. Whole fish were purchased whenever possible to ensure gonad samples were collected, but reproductive information was not available from all samples as some fish had been gutted prior to purchase. FL was measured to the nearest $\mathrm{mm}$, and otoliths and gonads were removed from each individual. Samples were not available from all months in each year due to the opportunistic nature of sample collection.

Sample processing. Otoliths were sectioned and read using the same methods applied to other serranids from the GBR and TS (see Ferreira \& Russ 1994, Pears et al. 2006, Williams et al. 2008b). Opaque increments were assumed to be formed annually based on the validation of this assumption for a wide range of other serranids (e.g. Ferreira \& Russ 1994, Mosse 2001, Pears et al. 2006). All sectioned otoliths were read twice by a single experienced reader, and the count of opaque increments was accepted as the fish's age in years if the 2 readings were the same. A third count was made by the same reader if the first 2 counts differed, and a match between the third and either of the first 2 counts was accepted as the fish's age. The median count was assigned as the final age estimate for those otoliths $(18 \%)$ from which there was no agreement among 3 counts.

Gonads from fish collected from the GBR were removed and preserved at sea in $10 \%$ phosphatebuffered formalin. Gonads from fish collected by observers in the TS were frozen immediately after removal and transported to the laboratory to be preserved. Gonads from fish purchased from the TS were removed from frozen fish and preserved in the labora-

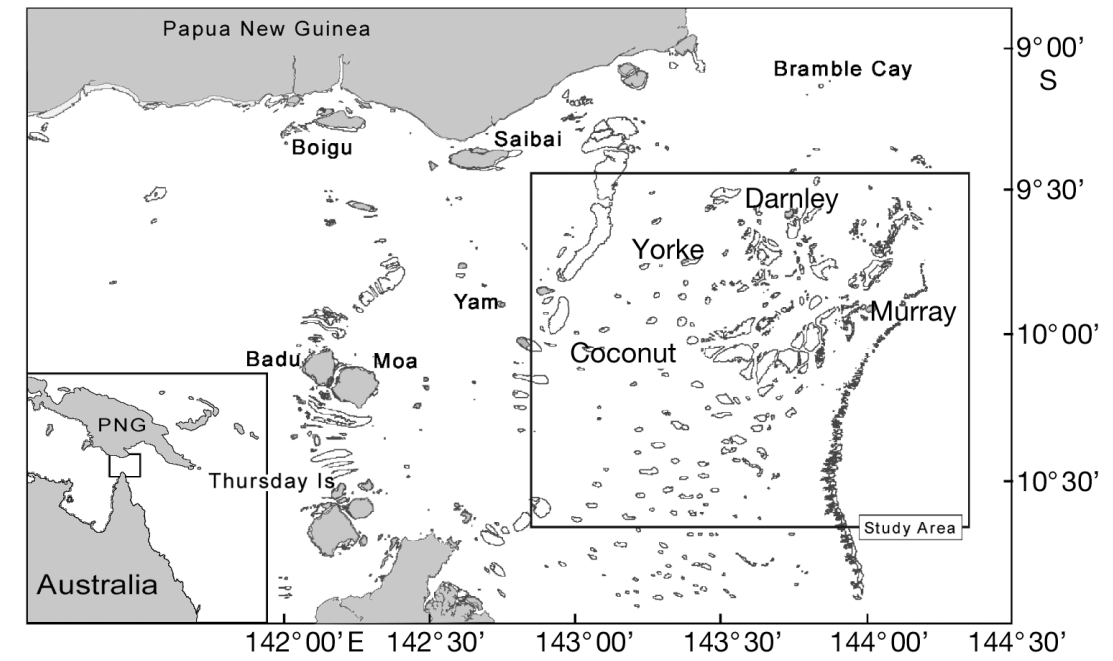

Fig. 2. Torres Strait, indicating the location of the reefs sampled (study area). All samples were collected east of $142^{\circ} 31^{\prime} 49^{\prime \prime} \mathrm{E}$, as commercial fishing is prohibited west of this line 
tory. All gonads were preserved in $10 \%$ phosphate buffered formalin. Each pair of gonads was dried of excess fixative after fixation, and gonad weight was measured to the nearest $0.1 \mathrm{~g}$. Total gonad weight was estimated by multiplying the mass of a single complete lobe by 2 where 1 gonad lobe was damaged during processing. It was assumed that this provided a reasonably accurate measure of gonad weight because the 2 gonad lobes are generally equal in size for other serranid species (Adams 2003).

Histological sections were taken from all gonads following the procedures outlined by Adams (2003). The stage of ovary development was based on the most advanced non-atretic cell type present (West 1990). Additional features used in histological staging included the presence of brown bodies, atretic oocytes, vascularisation, and the relative thickness of the gonad wall, all of which may indicate prior spawning (Sadovy \& Shapiro 1987). Ovaries and testes were classified into reproductive developmental stages adapted from Ferreira (1995) and Adams (2003). Females were classified into 4 stages: Immature, Resting, Ripe, and Running Ripe (hydrated). Males were classified into 3 stages: Resting, Ripe, and Spent. Transitional (fish in the process of changing sex from female to male) individuals were also identified using the criteria described by Sadovy \& Shapiro (1987).

Demographic analyses. The relationship between $F L$ and $W$ was described using a power function of the form

$$
W=a \times F L^{b}
$$

where $a$ is the coefficient of the power function and $b$ is the exponent. This relationship was compared between populations from the GBR and TS using analysis of covariance (ANCOVA) with ln FL as the covariate of $\ln W$.

Length and age frequency distributions of Cromileptes altivelis were compared between the GBR and TS using multi-dimensional contingency tables using the same range of length (340 to $660 \mathrm{~mm}$ ) and age ( 3 to $14 \mathrm{yr}$ ) classes for each region.

The von Bertalanffy growth function (VBGF) was fitted by nonlinear least-squares regression of $F L$ on age of Cromileptes altivelis from the GBR and TS. The form of the VBGF used to model length-at-age data was

$$
L_{t}=L_{\infty}\left(1-\mathrm{e}^{-K\left(t-t_{0}\right)}\right)
$$

where $L_{t}$ is the length at age $t_{1} L_{\infty}$ is the mean asymptotic $F L, K$ is the growth coefficient or rate at which $L_{\infty}$ is approached, $t$ is the age of the fish and $t_{0}$ is the age at which the fish have a theoretical length of 0 . This form of the VBGF is most commonly used to describe the growth of teleosts given their very small size at birth compared to other taxa (Haddon 2001). Alternative parameterisations of the VBGF were tested but revealed very small differences in parameter estimates. A constrained VBGF was also fitted to the length-at-age data, where $t_{0}$ was constrained to 0 , as a sensitivity analysis, given the lack of smaller, younger fish in the samples.

VBGFs were compared between the GBR and TS using likelihood ratio tests (Kimura 1980). A common range of age classes (3 to $15 \mathrm{yr}$ ) was used in each analysis to assure validity of the comparisons (Haddon 2001).

Age-based catch curves (Ricker 1975) were used to estimate the instantaneous rate of total mortality $(Z)$ for Cromileptes altivelis from the GBR and TS. Catch curves are generated by fitting a linear regression to the natural logarithm of the number of individuals of each age class against fish age. The slope of this regression is an estimate of the rate of annual mortality. The use of catch curves is subject to a number of assumptions, including (1) the population is sampled representatively; (2) the regression only includes fish fully recruited to the sampling gear; (3) mortality is constant among age classes and over time; and (4) recruitment is the same each year. Regressions were fitted from age 6 yr (assumed full selectivity) through to the oldest age class that was preceded by no more than 2 consecutive 0 frequencies. Estimates were compared between the GBR and TS using ANCOVA with age as the covariate and data limited to a common age range of 6 to $16 \mathrm{yr}$. A catch curve was also fitted to age frequency data from reefs closed to fishing on the GBR to provide an estimate of natural mortality $(M)$ for $C$. altivelis assuming that these reefs had not been subjected to significant levels of infringements. An additional estimate of $M$ was obtained by fitting the linear equation $\ln (Z)=1.44-0.982 \times \ln \left(t_{\max }\right)$ developed by Hoenig (1983) to the maximum age observed, $t_{\max }$ (19 yr), obtained from reefs closed to fishing, and assuming the estimate of $Z$ approximated $M$.

Reproductive biology. The spawning season for Cromileptes altivelis from the GBR and TS was examined using samples collected in different months throughout the year. A gonadosomatic index (GSI = gonad weight $/ W \times 100$ ) was calculated for each sample, providing a relative measure of reproductive stage. The proportion of samples in each mature female and male reproductive stage in each month was plotted for each region to examine the ovarian and testicular development patterns throughout the year and the degree of spawning activity occurring in each month in each region.

A logistic function was fitted to the proportion of males in each length and age class to estimate the length and age at which Cromileptes altivelis changes sex. The length and age at sex change was estimated for the GBR and TS using the logistic equation 


$$
P_{S}=\left(1+\mathrm{e}^{-\ln 19\left(s-s_{50}\right) /\left(s_{95}-s_{50}\right)}\right)^{-1}
$$

where $P_{S}$ is the proportion of males in age or $10 \mathrm{~mm}$ length class $S_{1}$ and $S_{50}$ and $S_{95}$ are the age or length at which 50 and $95 \%$ of the population are males, respectively. Transitional individuals were not included in these analyses, but their presence or absence in each length and age class provided an additional estimate of the length and age range over which sex change occurred. Likelihood ratio tests were used to test for differences in the length and age at sex change between the GBR and TS using a common age or length range for each region to assure validity of the comparisons (Haddon 2001).

The sex assigned from histology for samples collected by researchers during observer surveys in the TS or ELF catch surveys on the GBR was used to calculate the operational sex ratio (mature females to mature males) for Cromileptes altivelis from the GBR and TS. Sex ratios were compared between the GBR and TS using a chi-squared contingency test and compared to an expected ratio of $1: 1$ with a chi-squared goodness of fit test.

\section{RESULTS}

\section{Length and age distributions}

The modal length of Cromileptes altivelis was the same $(500 \mathrm{~mm})$ for the GBR and TS, and a multidimensional contingency table analysis indicated that the length distributions did not vary significantly between regions $\left(\chi^{2}=23.75, \mathrm{df}=15, \mathrm{p}=0.07\right)$. Therefore, length data were pooled across regions to produce a length frequency distribution for the combined data (Fig. 3). The modal age of $C$. altivelis differed between regions and was 6 yr for the GBR and 9 yr for TS. The maximum age from the GBR (19 yr) was slightly older than from TS (16 yr). Despite different modes and maximum age, multi-dimensional contingency table analyses indicated that the age distributions did not differ significantly between the regions $\left(\chi^{2}=11.61, \mathrm{df}=11, \mathrm{p}=0.39\right)$. Age data were pooled across regions to produce an age frequency distribution for the combined data (Fig. 3).

\section{Growth and mortality}

The relationship between $F L$ and $W$ was approximately isometric for Cromileptes altivelis from both regions (Table 1) and did not differ significantly between them (ANCOVA, $F=0.17$, df =1, p =0.68), so data were pooled to provide an estimate of the $F L-W$ relationship (Fig. 4, Table 1).

There was substantial variation in the length-at-age of Cromileptes altivelis within the GBR and TS. The parameter estimates for the VBGF indicated a greater average maximum size $\left(L_{\infty}\right)$ and lower growth coefficient $(K)$ for the GBR than the TS (Table 1) but the likelihood ratio tests indicated that these differences were not significant $\left(\chi^{2}=4.81, \mathrm{df}=3, \mathrm{p}=0.19\right)$. The unconstrained growth curve for the pooled data across regions was relatively 'flat', as few fish smaller than $400 \mathrm{~mm} F L$ were sampled (Fig. 5). Therefore, VBGF parameter estimates from the unconstrained fit are likely to be biased, with an overestimate of $L_{\infty}$ and underestimate of $K$ and $t_{0}$. The constrained fit of the VBGF resulted in a lower $L_{\infty}$ and higher $K$ and $t_{0}$ than the unconstrained fit (Fig. 5). It is important to note, however, that the parameter estimates from the constrained fit may also be
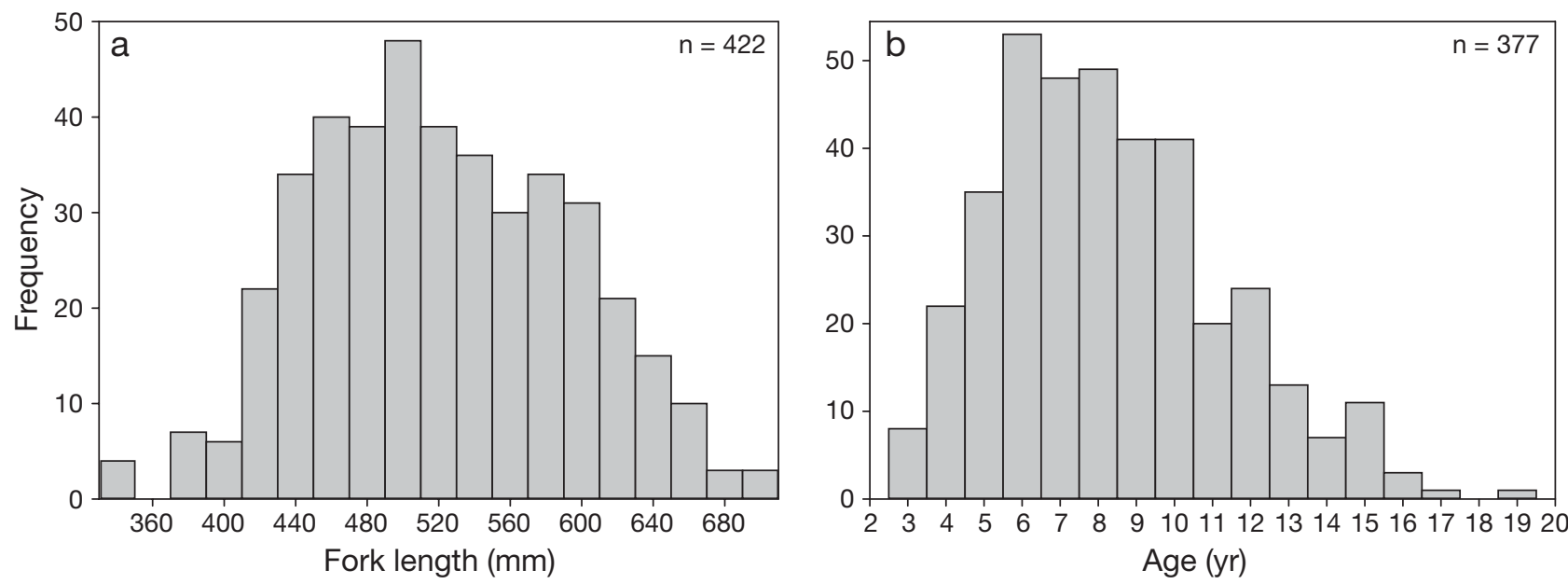

Fig. 3. Cromileptes altivelis. (a) Length and (b) age frequency distributions from data pooled across the Great Barrier Reef and Torres Strait. n: number of grouper sampled 
Table 1. Cromileptes altivelis. Parameter estimates $( \pm \mathrm{SE})$ for the length-weight relationship, constrained $\left(t_{0}=0\right)$ and unconstrained von Bertalanffy growth function (VBGF) and rates of total $(Z)$ and natural $(M)$ mortality ( $\mathrm{yr}^{-1}$; estimated from catch curves and the method of Hoenig 1983) from the Great Barrier Reef, Torres Strait and pooled across regions. $a$ and $b$ : parameters of the allometric relationship $\left(W=\mathrm{a} \times F L^{b}\right)$ between fork length $(F L)$ and weight $(W)_{i} L_{\infty}$ : mean asymptotic $F L$ (mm); $K$ : growth coefficient $\left(\mathrm{yr}^{-1}\right) ; t_{0}$ : theoretical age $(\mathrm{yr})$ at length 0 for the VBGF; $n$ : number of samples used to estimate each parameter; na: not available

\begin{tabular}{|c|c|c|c|c|}
\hline Function & Parameter & Great Barrier Reef & Torres Strait & Pooled \\
\hline \multirow[t]{3}{*}{ Length-weight relationship } & $a\left(\times 10^{-9}\right)$ & $2.85(1.27)$ & $2.63(3.22)$ & $3.48(1.50)$ \\
\hline & $b$ & $3.27(0.07)$ & $3.29(0.19)$ & $3.24(0.07)$ \\
\hline & $n$ & 127 & 43 & 170 \\
\hline \multirow[t]{4}{*}{ VBGF, unconstrained } & $L_{\infty}$ & $735(114)$ & $625(52)$ & $696(72)$ \\
\hline & $K$ & $0.08(0.05)$ & $0.13(0.07)$ & $0.09(0.04)$ \\
\hline & $t_{0}$ & $-6.96(3.97)$ & $-6.79(4.19)$ & $-8.00(3.39)$ \\
\hline & $n$ & 180 & 196 & 376 \\
\hline \multirow[t]{3}{*}{ VBGF, constrained $\left(t_{0}=0\right)$} & $L_{\infty}$ & $597(11)$ & $558(7)$ & $575(6)$ \\
\hline & $K$ & $0.30(0.02)$ & $0.40(0.03)$ & $0.35(0.02)$ \\
\hline & $t_{0}$ & 0 & 0 & 0 \\
\hline \multirow[t]{2}{*}{ Total mortality, catch curve } & $Z$ & $0.27(0.03)$ & $0.25(0.04)$ & $0.26(0.03)$ \\
\hline & $n$ & 152 & 160 & 310 \\
\hline \multirow[t]{2}{*}{ Natural mortality, catch curve } & $M$ & $0.26(0.02)$ & na & na \\
\hline & $n$ & 113 & & \\
\hline Natural mortality, Hoenig & $M$ & 0.23 & na & na \\
\hline
\end{tabular}

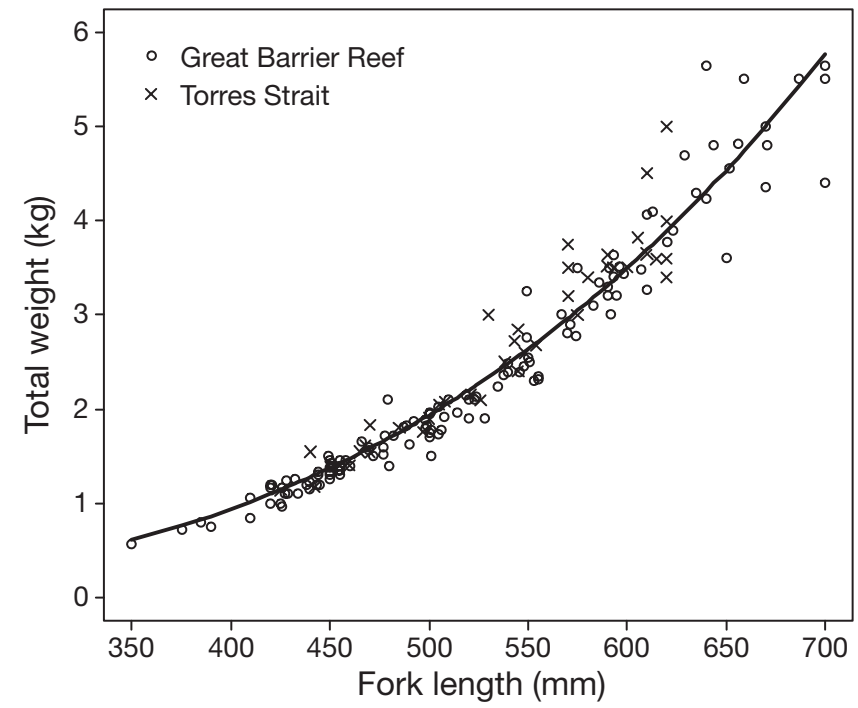

Fig. 4. Cromileptes altivelis. Weight-at-length data and fitted power curves from the Great Barrier Reef and Torres Strait

biased, resulting in an underestimate of $L_{\infty}$ and overestimate of $K$. The average lengths at age for $10 \mathrm{wk}$, 1 and 2 yr old fish, based on data from Liu \& Sadovy de Mitcheson (2009), are plotted in Fig. 5. These data demonstrate the likely better fit of the constrained VBGF to early growth of $C$. altivelis.

The estimate of total mortality $(Z)$ for Cromileptes altivelis was similar between the TS $\left(0.25 \mathrm{yr}^{-1}\right)$ and the GBR (0.27 $\mathrm{yr}^{-1}$; Table 1$)$ and did not differ significantly between the regions (ANCOVA, $F=0.42, \mathrm{df}=1, \mathrm{p}=$ $0.68)$, so data were pooled across regions to provide an overall estimate of $Z\left(0.26 \mathrm{yr}^{-1}\right)$. The estimate of $M$

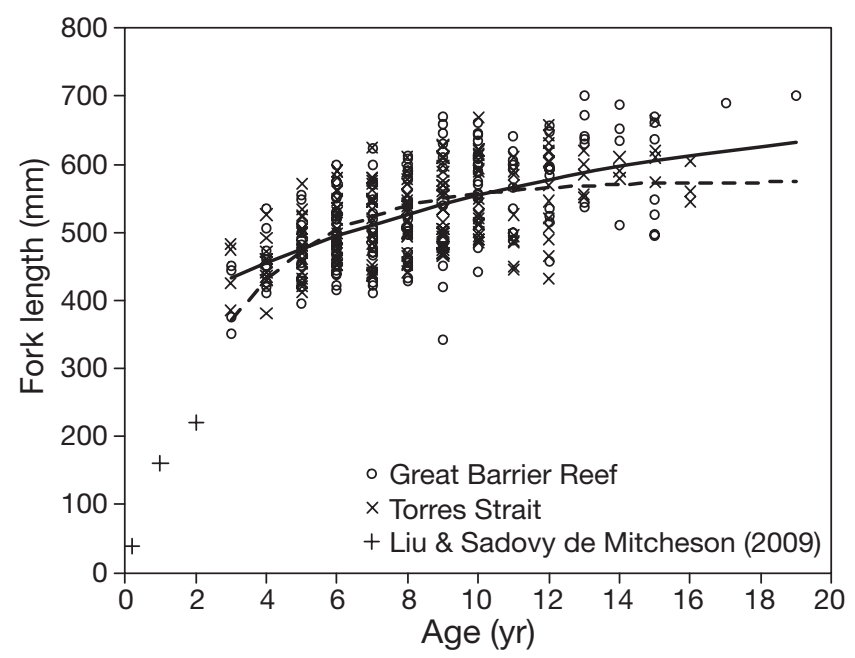

Fig. 5. Cromileptes altivelis. Length-at-age data from the Great Barrier Reef and Torres Strait. Solid line is unconstrained von Bertalanffy growth function (VBGF) fit to data pooled across regions, dashed line is constrained VBGF fit (theoretical age at length $0, t_{0}=0$ ). Average length-at-age for $10 \mathrm{wk}$ old, 1 and 2 yr old fish from Liu \& Sadovy de Mitcheson (2009)

obtained by fitting a catch curve to age frequency data from reefs closed to fishing on the GBR and from fitting Hoenig's (1983) equation was $0.26 \mathrm{yr}^{-1}$ and $0.23 \mathrm{yr}^{-1}$, respectively (Table 1 ).

\section{Reproductive biology}

The monthly trends in GSI and mature ovarian and testicular stages indicated that the peak spawning months differed between the GBR and TS. Mean 
monthly GSI values for mature females were highest in December-January on the GBR and October-November in the TS (Fig. 6). The mean monthly GSI values for males were more variable than for females but were generally highest from October to March in both regions (Fig. 7).

The monthly trend in the frequency of mature ovarian stages (ovaries in active vitellogenesis) also suggested a different temporal pattern in spawning activity for the GBR and TS (Fig. 6). The majority of spawning activity, indicated by the presence of ripe and running ripe females, occurred in December-January on the GBR, but was protracted across the months October to January in the TS (Fig. 6). The monthly

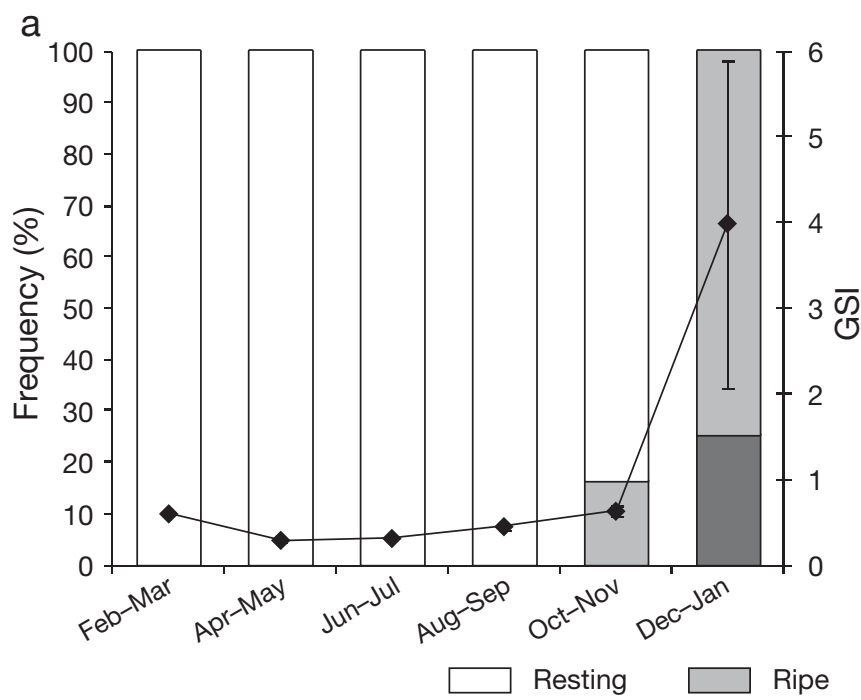

trend in the frequency of testicular stages indicated that males in both regions were capable of spawning over an extended period on either side of the spawning season indicated by the presence of active females (Fig. 7).

There was a large overlap in the length and age of male and female Cromileptes altivelis from the GBR and TS, although females generally dominated the smaller length classes and younger age classes and males dominated the larger length classes and older age classes (Fig. 8). Transitional individuals were relatively common on the GBR, but rare in TS. No immature individuals were sampled from either region.

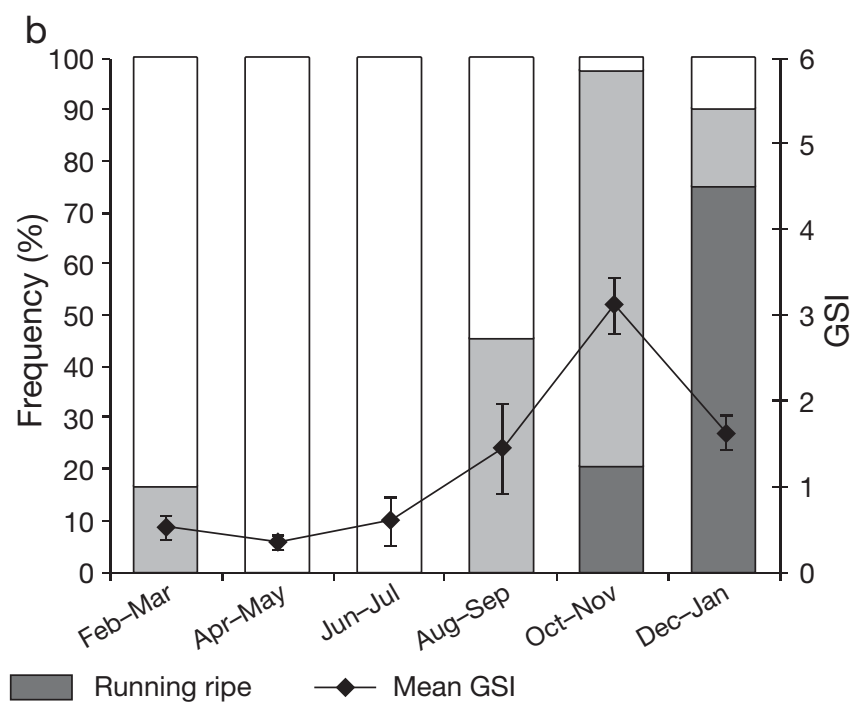

Fig. 6. Cromileptes altivelis. Monthly frequencies of mature ovarian stages and mean monthly gonadosomatic index (GSI) values for females from (a) the Great Barrier Reef and (b) the Torres Strait. Error bars are SE
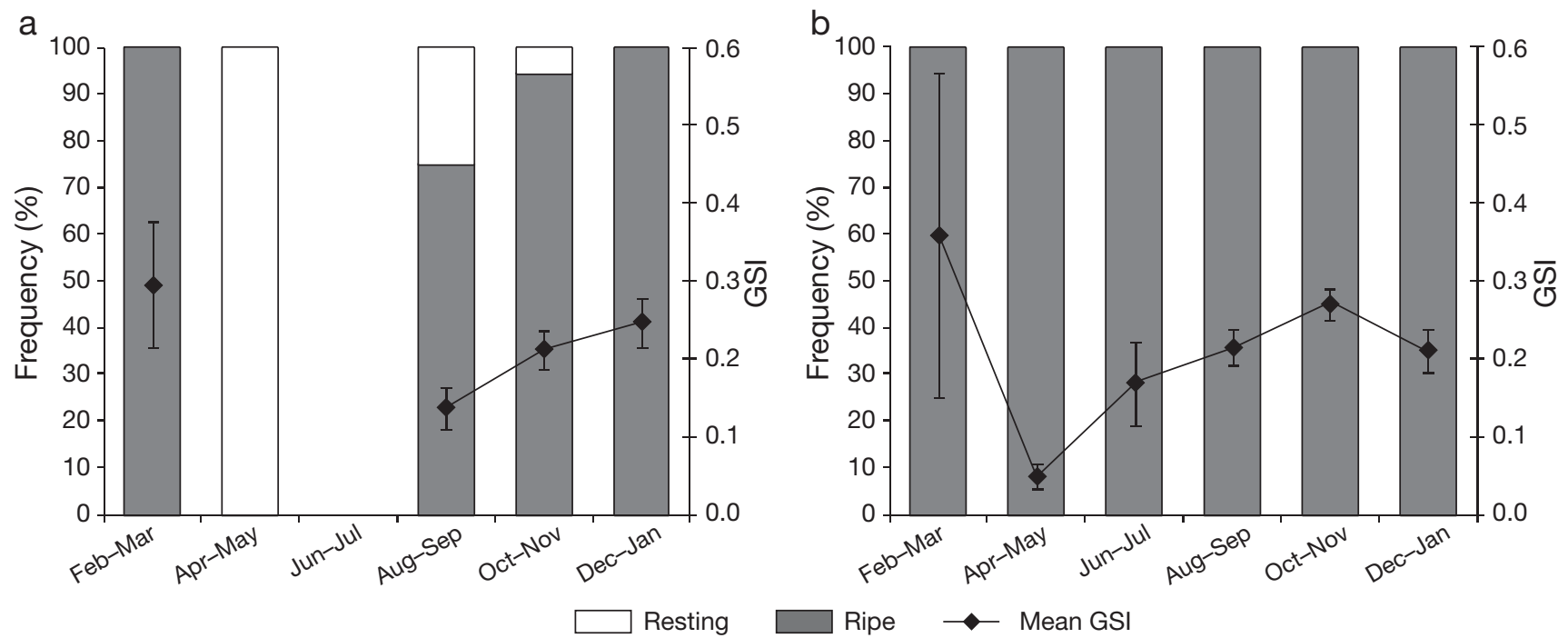

Fig. 7. Cromileptes altivelis. Monthly frequencies of testicular stages and mean monthly gonadosomatic index (GSI) values for males from (a) the Great Barrier Reef and (b) the Torres Strait. Error bars are SE 

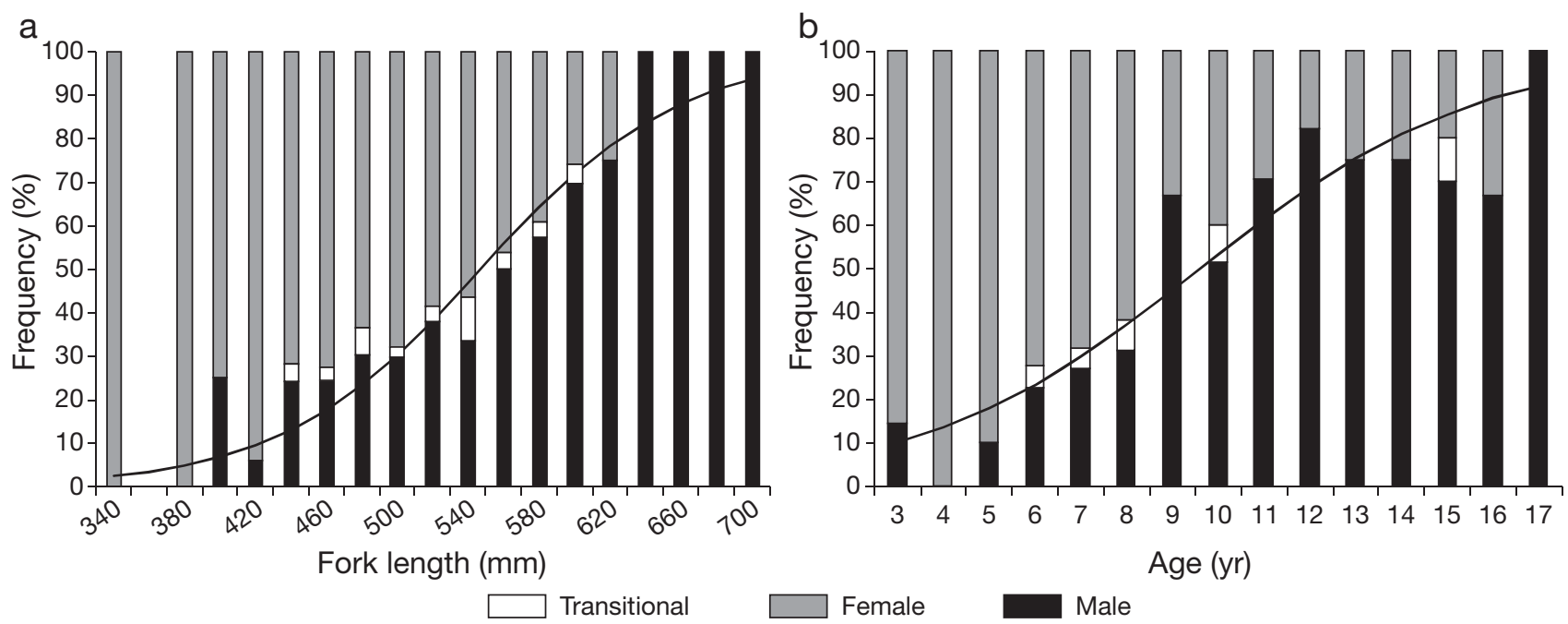

Fig. 8. Cromileptes altivelis. Proportion of male, transitional and mature females in each (a) size and (b) age class and estimated logistic function (line) fitted to the proportion of males from the Great Barrier Reef and Torres Strait. Parameters of the logistic functions are given in Table 2

The estimated length and age at which 50 and $95 \%$ of individuals changed sex was very similar between the GBR and TS (Table 2). Likelihood ratio tests indicated that the pattern in the length and age at sex change was similar between the GBR and TS (length: $\chi^{2}=0.25$, df $=2, \mathrm{p}=0.88$; age: $\chi^{2}=0.26$, df $=2, p=0.88$ ). Sex ratio for Cromileptes altivelis also did not differ significantly between regions (contingency table, $\chi^{2}=0.42$, $\mathrm{df}=$ $1, \mathrm{p}=0.52)$. Data were pooled across regions, and the sex ratio for the combined data was significantly female-biased (Table 2, goodness of fit test, $\left.\chi^{2}=6.19, \mathrm{df}=1, \mathrm{p}=0.01\right)$.

Table 2. Cromileptes altivelis. Peak spawning months, sex ratios and parameter estimates $( \pm \mathrm{SE})$ of age and length-specific sex change from the Great Barrier Reef, Torres Strait and pooled across regions. $L_{50}$ and $L_{95}$ : estimated length (mm $F L$ ) at which 50 and $95 \%$ of the population are males, respectively; $A_{50}$ and $A_{95}$ : estimated age (yr) at which 50 and $95 \%$ of the population are males, respectively; $n$ : number of samples used to estimate each parameter

\begin{tabular}{lccc|}
$\begin{array}{l}\text { Parameter } \\
\text { Peak spawning months }\end{array}$ & $\begin{array}{c}\text { Great Barrier Reef } \\
\text { Dec-Jan }\end{array}$ & $\begin{array}{c}\text { Torres Strait } \\
\text { Oct-Jan }\end{array}$ & $\begin{array}{c}\text { Pooled } \\
\text { Oct-Jan }\end{array}$ \\
\hline $\begin{array}{l}\text { Sex ratio (F:M) } \\
n\end{array}$ & $1.22: 1$ & $1.41: 1$ & $1.32: 1$ \\
Length-specific sex change & 151 & 176 & 327 \\
$L_{50}$ & $549(8)$ & $545(8)$ & $547(8)$ \\
$L_{95}$ & $715(24)$ & $715(27)$ & $713(22)$ \\
$n$ & 151 & 176 & 327 \\
Age-specific sex change & & & \\
$A_{50}$ & $9.7(0.7)$ & $9.5(0.7)$ & $9.6(0.5)$ \\
$A_{95}$ & $17.9(2.1)$ & $18.0(2.2)$ & $18.6(1.6)$ \\
$n$ & 131 & 176 & 307 \\
\hline
\end{tabular}

\section{DISCUSSION}

Our study provides the first age-based estimates of demographic parameters for Cromileptes altivelis and provides a foundation for formal assessments of the effects of fishing and evaluation of the likely performance of alternative management and conservation efforts for this species. The biological characteristics of C. altivelis (moderate longevity, relatively fast initial growth, moderate total mortality rates and early maturity) suggest that this species may not be as vulnerable to managed fishing pressure as previously thought. The apparently low natural levels of abundance of $C$. altivelis (Sabetian 2003, Pears 2005), however, suggest that reproductive output, recruitment processes, or a combination of both, may be limiting factors for the productivity of $C$. altivelis populations. In the absence of robust estimates of recruitment and unexploited post-settlement abundance and evidence of rapid depletion of C. altivelis stocks, it would seem prudent to maintain/implement appropriately conservative management measures.

Serranids, including Cromileptes altivelis, have generally been thought to be long-lived fishes (Manooch 1987, Sadovy et al. 2003) but recent studies have demonstrated that longevity within serranids varies greatly from $<10$ yr to $>40$ yr (e.g. Ferreira \& Russ 
1994, Mosse 2001, Grandcourt 2002, Pears 2005, Pears et al. 2006). C. altivelis from the GBR and TS is a moderately long-lived serranid with a life span approaching 20 yr. This is a shorter lifespan than that of other medium to large serranids such as Epinephelus polyphekadion and E. fuscoguttatus that live around 40 yr (Pears 2005, Pears et al. 2006) and is counter to previous perceptions that this species is particularly long-lived (e.g. Morris et al. 2000). The longevity of $C$. altivelis is similar to the coral trout species Plectropomus leopardus, $P$. areolatus and $P$. laevis, the main reef fishes targeted by many fisheries in the Indo-Pacific. These species have a reported longevity between 14 and 18 yr (Ferreira \& Russ 1994, Williams et al. 2008b, Heupel et al. in press).

The growth pattern for Cromileptes altivelis is similar to many other serranids that are characterised by large variation in size-at-age and reach about $80 \%$ of their average maximum size $\left(L_{\infty}\right)$ within the first quarter of their lifespan (e.g. Ferreira \& Russ 1994, Mosse 2001, Pears 2005, Pears et al. 2006). Consequently, the relationship between age and size is weak, with the exception of the first 1 or 2 age-classes. As a result, length data alone are of limited value for estimating life history parameters and assessing the state of the stock and potential effects of different harvest strategies. The distribution of length data, however, indicates that fish $<430 \mathrm{~mm}$ TL were not fully selected by the fishing gear used in this study. Hence, the estimated growth parameters are likely to be biased, relative to the 'true' pattern of growth, due to the lack of small fish and likely sampling bias towards fastergrowing individuals in the younger age classes. The constrained and unconstrained fits of the VBGF to the size-at-age data provide an indication of the likely extremes of the growth pattern for C. altivelis, although the true growth pattern most likely lies somewhere between the 2 fits. Length-at-age data from hatchery reared $C$. altivelis reported by Liu \& Sadovy de Mitcheson (2009) indicate that our constrained VBGF is more likely to reflect the early pattern of growth of $C$. altivelis, although these data can be expected to be biased by hatchery conditions.

Published estimates of $Z$ vary widely among serranids, reflecting the wide range of longevities among species, the difficulty in estimating mortality rates using catch curves and, presumably, the wide variation in fishing mortality among study locations. Estimates of $Z$ for Plectropomus leopardus, which has a similar longevity to Cromileptes altivelis and is the main target species on the GBR and TS, range from 0.12 to 0.68 (Brown et al. 1994, Russ et al. 1998, Mapstone et al. 2004, Bergenius 2007), encompassing the range of estimates for $C$. altivelis in our study. It is difficult to partition estimates of $Z$ into its components of natural mor- tality $(M)$ and fishing mortality $(F)$, which are necessary to estimate the likely impacts of different levels of exploitation. The estimate of $Z$ for $C$. altivelis from the GBR was based primarily on data from reefs closed to fishing for 10 to $12 \mathrm{yr}$ prior to the first sampling in 1995. Excluding the data from open reefs resulted in a very similar estimate of mortality from catch curves $\left(0.26 \mathrm{yr}^{-1}\right)$ and Hoenig's (1983) equation, which can be assumed to provide an indication of the likely values of $M$, assuming no infringement and 0 adult movement among reefs. The very similar estimates of $Z$ for the GBR and TS $\left(0.25\right.$ to $\left.0.27 \mathrm{yr}^{-1}\right)$ and the negligible difference between the estimates of $M$ and $Z$ suggest that current (in the TS) or recent past (on the GBR) fishing mortality on these populations is low.

Most serranids are considered to be late maturing, with first maturity (smallest length at which maturation is observed) reached at approximately $50 \%$ of average maximum size but ranging between 33 and $74 \%$ (Sadovy 1996). The absence of immature Cromileptes altivelis in our study means it is difficult to make rigorous comparisons of the maturity schedule for this species to that of other serranids. Liu \& Sadovy de Mitcheson (2009) reported the length at first maturity for $C$. altivelis under culture conditions to be $155 \mathrm{~mm}$ FL. Although these estimates will have been influenced by culture conditions to some degree, they are consistent with our results. The smallest (mature) female C. altivelis we sampled was $350 \mathrm{~mm} \mathrm{FL}$, suggesting that $100 \%$ of the population above this size is mature and that the size at first (and $50 \%$ ) maturity occurs at a smaller size. On the basis of these results, we conclude that $C$. altivelis appears to reach first maturity at approximately $27 \%$ (i.e. $155 \mathrm{~mm} / 575 \mathrm{~mm}$ ) of its average maximum length, which is smaller than for other serranids reported by Sadovy (1996). Information on age at maturity for serranids is more limited. Liu \& Sadovy de Mitcheson (2009) estimate the age at first maturity for C. altivelis under culture conditions to be $1.6 \mathrm{yr}$, which is consistent with the youngest (mature) female C. altivelis that we sampled at 3 yr of age. The preliminary results suggest that $C$. altivelis matures at approximately 8 to $16 \%$ of potential life span (19 yr) and is likely to have a relatively long reproductive life (up to $17 \mathrm{yr}$ ). Further sampling of smaller and younger individuals is required to provide more accurate estimates of the size and age maturity schedules for $C$. altivelis.

Observations from underwater visual surveys (Sabetian 2003, Pears 2005) suggest that Cromileptes altivelis usually occur as individuals or pairs and do not form large spawning aggregations like many other medium- to large-sized serranids (Sadovy 1996). Spawning behaviour has been reported for a number of serranid species (e.g. Sadovy et al. 1994, Coleman et al. 1996, Samoilys 1997, Sluka 2001, Whaylen et al. 
2004, Matos-Caraballo et al. 2006), but C. altivelis spawning in the wild has not been documented (Morris et al. 2000). Spawning has been observed in captivity at Indonesian aquaculture facilities, where it occurred throughout most of the year (Mous 2000, Sugama et al. 2003), but these observations are from 1 equatorial location and are likely to be strongly influenced by culture conditions. Hence, they are unlikely to be representative of patterns in the wild or variation across the species' range. Peak periods of spawning activity of $C$. altivelis in the TS were identified to occur in the months of October through January, while peak spawning on the GBR was restricted to December and January. This is consistent with general patterns of reef fish reproduction whereby spawning seasons commence earlier and are more protracted at lower than at higher latitudes (e.g. Kokita 2004).

The sexual development pathway for Cromileptes altivelis was unconfirmed prior to our study but assumed to be protogyny, as in most other serranids (Sadovy et al. 2008). We have confirmed that $C$. altivelis is a protogynous hermaphrodite through histological analyses that have revealed a bimodal size and age distribution by sex (with males larger and older than females) and transitional individuals, all of which are necessary features to confirm protogyny (Sadovy \& Shapiro 1987). C. altivelis was found to change sex (on average) at around $95 \%$ of the average maximum length ( $L_{\infty}$ from the constrained VBGF fit) and around $50 \%$ of the potential maximum age. This is similar to other protogynous serranids in which sex change occurs close to the maximum size (e.g. Pears et al. 2006, Williams et al. 2008b).

Plasticity often exists in the timing of sex change for fish populations in different regions and locations (Adams et al. 2000, Gust 2004, Williams et al. 2006). The large overlap in the size and age of male and female Cromileptes altivelis and the presence of transitional individuals over several ages indicates that sex change is also flexible in this species. These characteristics may indicate social control of sex change whereby females are able to change sex to male to maintain some threshold sex ratio (Shapiro 1981, Ross et al. 1983, Sadovy \& Shapiro 1987, Cowen 1990, Vincent \& Sadovy 1998) rather than changing sex at a predetermined size or age. However, the controlling mechanism for sex change remains unclear and untested for the majority of protogynous fish (Sadovy 1996), including C. altivelis. Populations of protogynous species are typically female-biased (Sadovy 1996, Sadovy \& Shapiro 1987). The sex ratio of C. altivelis was only slightly female-biased (1.32:1), suggesting that the mating pattern may be monogamous, whereby a single male and single female pair-spawn consecutively. Observations of pairs of $C$. altivelis in the wild
(Sadovy et al. 2008) and pair-spawning of C. altivelis in captivity (Mous 2000) support this hypothesis.

\section{Implications for fisheries management and conservation}

Cromileptes altivelis is considered to be threatened by overfishing throughout most of its distribution due to the high demand from the live reef fish trade and the general lack of effective management measures for the species in many regions (Oakley et al. 1999, Morris et al. 2000, Sadovy et al. 2003, Teh et al. 2005). We provide essential biological information for evaluating the effects of fishing on $C$. altivelis populations and the likely performance of alternative management strategies. The results from the GBR and TS demonstrate that $C$. altivelis is likely to have similar rates of growth, mortality and size at first reproduction as other serranid species and, at face value, do not suggest that $C$. altivelis populations should be unusually vulnerable to fishing. However, the limited information on the natural level of abundance (low) and average levels of recruitment (low) suggests that the productivity of populations is likely to be low and that a conservative approach to management is appropriate until the uncertainty in some parameter estimates is reduced and more comprehensive location- and region-specific studies and monitoring programmes are established.

Estimates of biological parameters for Cromileptes altivelis from the TS were generally similar to those estimated for populations on the GBR, and the combined estimates provide a sound foundation for the future management of $C$. altivelis populations throughout the GBR and TS. The applicability of the biological information to other parts of the species' range is less clear. Given the wide range of latitude from which our samples came $\left(9.5\right.$ to $\left.21^{\circ} \mathrm{S}\right)$, we consider that the estimates of population parameters provided are a useful starting place for other regions in the absence of region- or population-specific data. However, we strongly recommend that local estimates of population parameters are obtained as a matter of priority. Given the significant regional and local variation in population parameters that is becoming increasingly apparent for tropical reef fish populations (e.g. Adams et al. 2000, Williams et al. 2003, 2006, Gust 2004, Bergenius 2007) and its potential importance in the dynamics of species with meta-population structures (Kritzer \& Davies 2005), estimates from local populations are likely to significantly improve assessments and advice for particular stocks.

Cromileptes altivelis is currently a no-take species on the GBR but is still subject to harvest in the TS. Fisheries management measures in the TS are likely to 
provide protection from recruitment overfishing and conservation risk and may provide a suitable default for managing harvests in other locations where management measures are currently insufficient or absent. A minimum legal size limit of $450 \mathrm{~mm} F L$ was implemented in the TS on the basis that it would allow $C$. altivelis to spawn at least once before becoming vulnerable to harvest by the fishery. Our data indicate that the current minimum legal size will achieve this objective, given that all individuals we sampled were mature and the smallest individual sampled was $350 \mathrm{~mm}$ FL. However, it is important in the case of hermaphroditic species to account for sex change when setting size limits to avoid the disproportionate removal of 1 sex (Alonzo \& Mangel 2004). Approximately $15 \%$ of $C$. altivelis individuals change sex prior to reaching $450 \mathrm{~mm} F L$, which provides some protection of males prior to becoming selected by the gear used in this fishery. The survival of released fish needs to be relatively high for a minimum legal size limit to be effective, however, and, preferably, gear regulations should limit selectivity of individuals below the minimum legal size to minimise the prospect of capture and release. The post-release survival of $C$. altivelis is unknown, but for the current study it is likely to be relatively high as $C$. altivelis is usually taken in relatively shallow water (Heemstra \& Randall 1999), reducing the incidence of barotrauma and increasing the probability of survival (Sumpton et al. 2008).

Closure of coral reef fisheries during peak spawning times has been advocated as an important management tool for protecting spawning aggregations and ensuring the sustainability of populations (e.g. Sadovy de Mitcheson et al. 2008). The relative efficacy of spawning closures, however, depends on numerous factors, including the aggregating behaviour of the species, predictability of locating aggregations, increased catchability during spawning times, and the presence of other management measures, such as catch, effort or size limits. Cromileptes altivelis is not known to aggregate in particular locations to feed or spawn, unlike many other serranids, and therefore is unlikely to be particularly vulnerable to targeted harvesting while spawning. Consequently, seasonal closures to fishing are unlikely to be a particularly efficient tool to protect $C$. altivelis populations from the effects of fishing. The implementation of no-take areas (areas closed to fishing) is likely to provide greater protection for $C$. altivelis than seasonal closures, in the absence of other management measures. Even so, it will be necessary to also manage the harvest outside closed areas if the objectives of management are to provide for sustainable harvest as well as reduce the conservation risk to the population (Hilborn et al. 2006, Mapstone et al. 2008).
The high demand for Cromileptes altivelis for the aquarium trade and live reef fish trade and the relatively low natural abundance of the species recommend a conservative approach to management of fisheries that harvest $C$. altivelis. The closure of some areas to harvest, to conserve a proportion of the spawning stock biomass, in addition to catch, effort and minimum size limits in areas open to fishing would appear to be a practical and appropriate combination of management measures to reduce the conservation risk to the species and improve long-term harvest. In practice, implementing restrictions on harvest, such as size limits and catch limits, is likely to be difficult to achieve in many developing nations, where a large proportion of global harvest of $C$. altivelis is taken and populations are at greatest conservation risk. In this context, no-take areas may be a more effective management tool for reducing the immediate conservation risk to local populations of $C$. altivelis in these regions in the short term.

Acknowledgements. Funding for this work came from the Cooperative Research Centre (CRC) for the Great Barrier Reef World Heritage Area, the CRC Torres Strait, the Australian Fisheries Research and Development Corporation (Projects 1997-124; 1998-131), the Great Barrier Reef Marine Park Authority, James Cook University and the Australian Government's Marine and Tropical Sciences Research Facility. We are grateful for the assistance of many commercial and indigenous fishers from the Great Barrier Reef and Torres Strait for accommodating observers on vessels and providing samples from their catch. This paper is a contribution from the CRC Reef Effects of Line Fishing Project.

\section{LITERATURE CITED}

Adams S (2003) Morphological ontogeny of the gonad of three plectropomid species through sex differentiation and transition. J Fish Biol 63:22-36

Adams S, Mapstone BD, Russ GR, Davies CR (2000) Geographic variation in the sex ratio, sex specific size, and age structure of Plectropomus leopardus (Serranidae) between reefs open and closed to fishing on the Great Barrier Reef. Can J Fish Aquat Sci 57:1448-1458

Alonzo SH, Mangel M (2004) The effects of size-selective fisheries on the stock dynamics of and sperm limitation in sexchanging fish. Fish Bull (Wash DC) 102:1-13

Bergenius MAJ (2007) Stock structure of a coral reef fish, Plectropomus leopardus: identification and implications for harvest strategy evaluation. PhD thesis, James Cook University, Townsville

Brown IW, Doherty P, Ferreira B, Keenan C and others (1994) Growth, reproduction and recruitment of Great Barrier Reef food fish stocks. Project No. 90/18, Fisheries Research and Development Corporation, Canberra

Coleman FC, Koenig CC, Collins LA (1996) Reproductive styles of shallow-water groupers (Pisces: Serranidae) in the eastern Gulf of Mexico and the consequences of fishing spawning aggregations. Environ Biol Fishes 47: 129-141

Cowen RK (1990) Sex change and life history patterns of the labrid, Semicossyphus pulcher, across an environmental gradient. Copeia 1990:787-795 
Craig MT, Hastings PA (2007) A molecular phylogeny of the groupers of the subfamily Epinephelinae (Serranidae) with a revised classification of the Epinephelini. Ichthyol Res 54:1-17

Ferreira BP (1995) Reproduction of the common coral trout Plectropomus leopardus (Serranidae: Epinephelinae) from the central and northern Great Barrier Reef, Australia. Bull Mar Sci 56:653-669

Ferreira BP, Russ GR (1994) Age validation and estimation of growth rate of the coral trout, Plectropomus leopardus (Lacepede, 1802) from Lizard Island, Northern Great Barrier Reef. Fish Bull (Wash DC) 92:46-57

Grandcourt EM (2002) Demographic characteristics of a selected Epineheline groupers (Family: Serranidae; Subfamily: Epinephelinae) from Aldabra Atoll, Seychelles. Atoll Res Bull 539:199-216

Gust N (2004) Variation in the population biology of protogynous coral reef fishes over tens of kilometres. Can J Fish Aquat Sci 61:205-218

Haddon M (2001) Modelling and quantitative methods in fisheries. Chapman \& Hall, London

Heemstra PC, Randall JE (1999) Serranidae. In: Carpenter KE, Niem V (eds) FAO species identification guide for fishery purposes. The living marine resources of the Western Central Pacific. Vol 4. Bony fishes, Part 2 (Mugilidae to Carangidae). FAO, Rome, p 2442-2548

Heupel MR, Williams AJ, Welch DJ, Davies CR, Adams S, Carlos G, Mapstone BD (in press) Demography of a large grouper, Plectropomus laevis: implications for fisheries management. Mar Freshw Res

Hilborn R, Micheli F, De Leo G (2006) Integrating marine protected areas with catch regulation. Can J Fish Aquat Sci 63:642-649

Hoenig JM (1983) Empirical use of longevity data to estimate mortality rates. Fish Bull (Wash DC) 82:898-902

Kimura DK (1980) Likelihood methods for the von Bertalanffy growth curve. Fish Bull (Wash DC) 77:765-776

Kokita T (2004) Latitudinal compensation in female reproductive rate of a geographically widespread reef fish. Environ Biol Fishes 71:213-224

Kritzer JP, Davies CR (2005) The implications of spatial variation in asymptotic body size for the dynamics of spatially structured reef fish populations: a simulation study. Ecol Model 182:49-65

Liu M, Sadovy de Mitcheson Y (2009) Gonad development during sexual differentiation in hatchery-produced orangespotted grouper (Epinephelus coioides) and humpback grouper (Cromileptes altivelis) (Pisces: Serranidae, Epinephelinae). Aquaculture 287:191-202

Manooch CS (1987) Age and growth of snappers and groupers. In: Polovina JJ, Ralston S (eds) Tropical snappers and groupers: biology and fisheries management. Westview Press, Boulder, $\mathrm{CO}$

Mapstone BD, Tobin A, Jones A, Begg GA (2003) A review of reef line fishing in the eastern Torres Strait. CRC Reef Research Centre, Townsville

Mapstone BD, Davies CR, Little LR, Punt AE and others (2004) The effects of line fishing on the Great Barrier Reef and evaluations of alternative potential management strategies. CRC Reef Research Centre Technical Report No. 52, CRC Reef Research Centre, Townsville

Mapstone BD, Little LR, Punt AE, Davies CR and others (2008) Management strategy evaluation for line fishing in the Great Barrier Reef: balancing conservation and multi-sector fishery objectives. Fish Res 94:315-329

Matos-Caraballo D, Posada JM, Luckhurst BE (2006) Fisherydependent evaluation of a spawning aggregation of tiger grouper (Mycteroperca tigris) at Vieques Island, Puerto Rico. Bull Mar Sci 79:1-16

Morris A, Roberts CM, Hawkins JP (2000) The threatened status of groupers (Epinephelinae). Biodivers Conserv 9: 919-942

Mosse JW (2001) Population biology of Cephalopholis cyanostigma (Serranidae) of the Great Barrier Reef, Australia. PhD thesis, James Cook University, Townsville

Mous P (2000) Natural spawning of Cromileptes altivelis in Komodo, Indonesia. Grouper News 9. Network of Aquaculture Centres in Asia-Pacific, Bangkok

Oakley S, Pilcher N, Atack K, Digges C and others (1999) Reefs under attack: the status of coral reefs of Sabah, East Malaysia. 4th Int Conf Mar Biol South China Sea, Quezon City

Pears RJ (2005) Comparative demography and assemblage structure of serranid fishes: implications for conservation and fisheries management. PhD thesis, James Cook University, Townsville

Pears RJ, Choat JH, Mapstone BD, Begg GA (2006) Demography of a large grouper, Epinephelus fuscoguttatus, from Australia's Great Barrier Reef: implications for fishery management. Mar Ecol Prog Ser 307:259-272

Pet-Soede L, Horuodono H, Sudarsono (2004) SARS and the live food fish trade in Indonesia: some anecdotes. Live Reef Fish Information Bulletin 12, Secretariat of the Pacific Community, Noumea

Ricker WE (1975) Computation and interpretation of biological statistics of fish populations. Bull Fish Res Board Can 191:1-382

Ross RM, Losey GS, Diamond M (1983) Sex change in a coralreef fish: dependence of stimulation and inhibition on relative size. Science 221:574-575

Russ GR, Lou DC, Higgs JB, Ferreira BP (1998) Mortality rate of a cohort of the coral trout, Plectropomus leopardus, in zones of the Great Barrier Reef Marine Park closed to fishing. Mar Freshw Res 49:507-511

Sabetian A (2003) The association of physical and environmental factors with abundance and distribution patterns of groupers around Kolombangara, Solomon Islands. Environ Biol Fishes 68:93-99

Sadovy YJ (1996) Reproduction of reef fishery species. In: Polunin NVC, Roberts CM (eds) Reef fisheries. Chapman \& Hall, London

Sadovy Y, Shapiro DY (1987) Criteria for the diagnosis of hermaphroditism in fishes. Copeia 1987:136-156

Sadovy Y, Rosario A, Román A (1994) Reproduction in an aggregating grouper, the red hind, Epinephelus guttatus. Environ Biol Fishes 41:269-286

Sadovy YJ, Donaldson TJ, Graham TR, McGilvray F and others (2003) While stocks last: the live reef food fish trade. Asian Development Bank, Manila

Sadovy Y, Thierry C, Choat JH, Cabanban AS (2008) Cromileptes altivelis. In: IUCN (ed) IUCN Red List of threatened species, Ver 2009. Available at: www.iucnredlist. org/details/39774/0

Sadovy de Mitcheson Y, Cornish A, Domeier M, Colin PL, Russell M, Lindeman KC (2008) A global baseline for spawning aggregations of reef fishes. Conserv Biol 22: 1233-1244

> Samoilys MA (1997) Periodicity of spawning aggregations of coral trout Plectropomus leopardus (Pisces: Serranidae) on the Great Barrier Reef. Mar Ecol Prog Ser 160:149-159

Samoilys M, Williams ME, Slade SJ (2002) Coral reef line fishery. In: Williams LE (ed) Queensland's fisheries resources: current condition and recent trends 1988-2000. QI02012. Department of Primary Industries Queensland, Brisbane 
Shapiro DY (1981) Size maturation and the social control of sex reversal in the coral reef fish Anthias squaminipinnis (Peters). J Zool 193:105-128

Sluka RD (2001) Grouper and Napoleon wrasse ecology in Laamu Atoll, Republic of the Maldives: Part 2. Timing, location and characteristics of spawning aggregations. Atoll Res Bull 492:15

Sugama K, Suko I, Shogo K, Rimmer MA (2003) Improvement of larval rearing technique for humpback grouper, Cromileptes altivelis. Aquac Asia 8:34-37

Sumpton W, Mayer D, Brown I, Sawynok B, McLennan M, Butcher A, Kirkwood J (2008) Investigation of movement and factors influencing post-release survival of linecaught coral reef fish using recreational tag-recapture data. Fish Res 92:189-195

Teh L, Cabanban AS, Sumaila UR (2005) The reef fisheries of Palau Banggi, Sabah: a preliminary profile and assessment of ecological and socio-economic sustainability. Fish Res 76:359-367

Vincent ACJ, Sadovy YJ (1998) Reproductive ecology in the conservation and management of fishes. In: Caro TM (ed) Behavioural ecology and conservation biology. Oxford University Press, New York

Editorial responsibility: David Hodgson,

University of Exeter, Cornwall Campus, UK
West G (1990) Methods of assessing ovarian development in fishes: a review. Aust J Mar Freshw Res 41:199-222

Whaylen L, Pattengil-Semmens CV, Semmens BX, Bush PG, Boardman MR (2004) Observations of a Nassau grouper, Epinephelus striatus, spawning aggregation site in Little Cayman, Cayman Islands, including multi-species spawning information. Environ Biol Fishes 70:305-313

Williams AJ, Davies CR, Mapstone BD, Russ GR (2003) Scales of spatial variation in demography of a large coral reef fish: an exception to the typical model? Fish Bull (Wash DC) 101:673-683

Williams AJ, Davies CR, Mapstone BD (2006) Regional patterns in reproductive biology of Lethrinus miniatus on the Great Barrier Reef. Mar Freshw Res 57:403-414

Williams AJ, Ballagh AC, Begg GA, Murchie CD, Currey L (2008a) Harvest patterns and effort dynamics of indigenous and non-indigenous commercial sectors of the eastern Torres Strait reef line fishery. Cont Shelf Res 28: $2117-2128$

Williams AJ, Currey L, Begg GA, Murchie CD, Ballagh AC (2008b) Population biology of coral trout species in the eastern Torres Strait: implications for fishery management. Cont Shelf Res 28:2129-2142

Submitted: July 6, 2009; Accepted: September 16, 2009 Proofs received from author(s): December 1, 2009 